\title{
POSSIBLE IMPLEMENTATIONS OF THE CLOUD-BASED DATA-CENTRIC IOT PILOT PLATFORMS FOR SMART CITIES AND AGRICULTURE
}

\author{
János Simon \\ Department of Technology, Faculty of Engineering, University of Szeged, Hungary \\ e-mail: simon@mk.u-szeged.hu
}

\begin{abstract}
The Internet of Things (IoT) is starting to appear everywhere in many shapes and forms. But security is one of the most crucial thing that could trip up the growth of the IoT. Following security principles used in enterprise computing can help clear that issue. Already there are more connected devices than people on the planet, according to leading researchers in this area. By 2020, there will be 50 billion connected devices, outnumbering people by more than 6 to 1 . Most of these devices will be controllable over the Internet, and they will increasingly be responsible for collecting and transmitting sensitive data. Today consumers might own an app that collects information on their exercise routine. In a few years, those same people might have an Internet-enabled medical device that continually delivers data to their doctor. In the wrong hands, data from home management systems could be used to assess user's whereabouts. Likewise, businesses could be vulnerable when they connect things like HVAC, irrigation, or commercial appliances.
\end{abstract}

Keywords: IoT, Smart city, Cloud platform

\section{INTRODUCTION}

Within this work, a documented remote control of heating via the http protocol has been made and a brief description of the Internet of Things paradigm and the smart home. The platform on which the work was made is the popular PC Raspberry Pi, with the Raspbian version of Linux [23]. Software has been written to run on Raspberry Pi (Python and bash shell) and a simple user interface in JavaScript and HTML. Raspberry Pi also spins the apache server on itself. There is also a simple demonstration with servos. PWM modulation was used to adjust the position of the valves. The introduction introduces a brief description of the fields to be processed, and IoT is described further. It is based on the technical performance itself and the description of the hardware part (Raspberry) and the software part with the code snippets. In conclusion, the proposed system improvements were suggested. [20]

Home Automation is the use and control of home appliances via remote control or automatically. For this purpose, the Internet of Things has recently started to be mentioned, ie, a network of sensors and actuators inside a home controlled by a central system that automates the home. It is estimated that by 2019, 68 million homes in America and Europe will be "smart homes". Also, it is assumed that up to 2020, 50 billion devices will be networked within the Internet of Things paradigm. Within this paradigm there is also the "smart lighting" discussed in this final work. $19 \%$ of the world's electricity consumption is used for lighting and $6 \%$ of greenhouse emissions comes from that energy. Smart lighting is a good way to minimize and save on lighting, with remote on and off lights. It also provides a greater level of comfort within the home itself. [22]

This theme was selected because of the ease of availability of the Raspberry Pi platform, due to the many open source codes and the interest of the same theme. The aim is to approach Raspberry Pi platform students, learn something about the Internet of Things paradigm and study smart homes as the coming new technology. 


\section{INTERNET OF THINGS PARADIGM}

In general, the term Internet of Things (internet stuff) was coined by British entrepreneur Kevin Asthon 1999. It is a network of facilities (electronics, software, sensors) that allows data collection and processing [15] [17]. This allows objects to be controlled over the existing network infrastructure. Objects can be, for example, cardiac implants, car-built sensors, smart home appliances, etc.

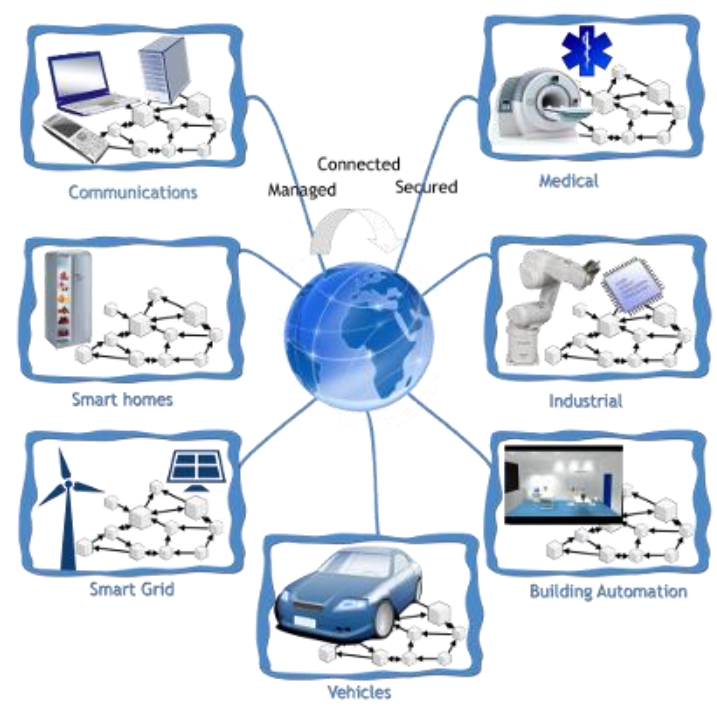

Figure 1. Internet of things paradigm

\section{SMART HOUSE BASICS}

An intelligent or smart house is a house that has a built-in central control system. Such a system is able to integrate multiple systems (heating, hot water consumption, cooling, lighting, safety).

The market for smart homes in 2015 is worth $\$ 5.77$ billion, while the forecast for 2020 is \$ 10 billion. Early home automation has started with energy-saving machines [4] [24].

Independent household appliances with electricity or gas became viable during the 1900s with the introduction of electricity distribution and led to the introduction of washing machines (1904), water heater (1889), refrigerators, sewing machines, dishwashers and dryers for clothing. In 1975, the first home automation technology for general purpose X10 was developed. It is a communication protocol for electronic devices. Primarily uses wiring harness for signaling and control. By 2012, in the United States, according to ABI Research, 1.5 million households installed [2] [10] [13].

According to [7], there are 3 generations of smart homes:

- First Generation: wireless technology with a proxy server, eg Zigbee, Z-Wave

- Second Generation: Artificial Intelligence that manages electrical appliances, eg Amazon Echo

- Third Generation: a robotic friend who communicates with people, eg Robot Rovio, Roomba.

The apps and technology that the Smart House is having are: [14]

- heating, ventilation and air conditioning (HVAC): remote control of all home energy monitors over the internet with a simple and friendly user interface

- Lighting control system 
- In-house control system: it is possible to know the current number of people using smart meters and environmental sensors such as $\mathrm{CO} 2$ sensors that can be integrated into the building automation system to increase energy efficiency

- device control and smart grid integration with a smart gauge, by exploiting, for example, high solar panel output in the middle of the day to start washing machines

- security: home security system integrated with the home automation system can provide additional services such as remote surveillance of security camera over the internet or central locking of all external doors and windows

- Flood detectors, smoke detectors and CO detectors.

Smart homes could bump into two types: [3]

- Complete house automation - houses / apartments designed before construction to be smart. These are expensive and advanced solutions, which can be wireless (Wi-Fi, Zigbee, Z-Wave) or wired (PLC Power Line Communication). Such systems work big companies, systems are closed and incompatible with others in the market. Examples of such systems are Creston, Control4, AMX, Elan Home Systems, HomeSeer.

- Non-invasive / consumer friendly home automation - inexpensive and user friendly solutions. The user usually obtains a central unit that collects data from the device and various plug and play devices that can be installed by themselves. Examples of such systems are Insteon, NEST, WeMo, Archos, Qivicon, Philips Hue, Iskon Smart Home.

The current biggest problem for smart home users is the unsafe systems (Wi-Fi and its vulnerability), and the fact that technology is still in peril, so users may buy devices, and after some time the manufacturer decides to abandon that service, shuts down servers and devices become useless [12][6] [18].

Also, the problem is lacking the right standards. There are many different and incompatible technologies where real IoT can not be achieved if all devices do not work together.

\section{RESULTS AND DISCUSSION}

MQTT is a communication protocol designed for use at the top of the TCP-IP protocol. It uses very little network traffic and is suitable for sensors that send their data to the "cloud". It requires connection to a type of dispatcher (Broker), who receives a subscriber of a particular sensor / device on a topic [5][16] [25].

The Message Queue Telemetry Transport Protocol (MQTT) was developed by Andy StanfordClark (IBM) and Arlen Nipper (Eurotech) in 1999 to track the pipeline in the middle of the desert. They needed a protocol that would enable efficient data transfer rates with low battery consumption and a cheaper overall system. Developed MQTT protocol with subscription - subscription to architecture has proven to be easier and more economical than HyperText Transfer Protocol (HTTP) protocol with request and response model. The Reveal Model - Subscription is triggered for events and allows customers to post messages without worrying about their final destination. The final destination of the posted message is determined by the MQTT broker who passes messages on the basis of client subscriptions and thus frees clients from sending requests for messages of interest, as opposed to the HTTP protocol where clients have to look for the information they need from the server. The MQTT protocol also features a small 2-byte fixed header size that further reduces network load [1][8][12]. 


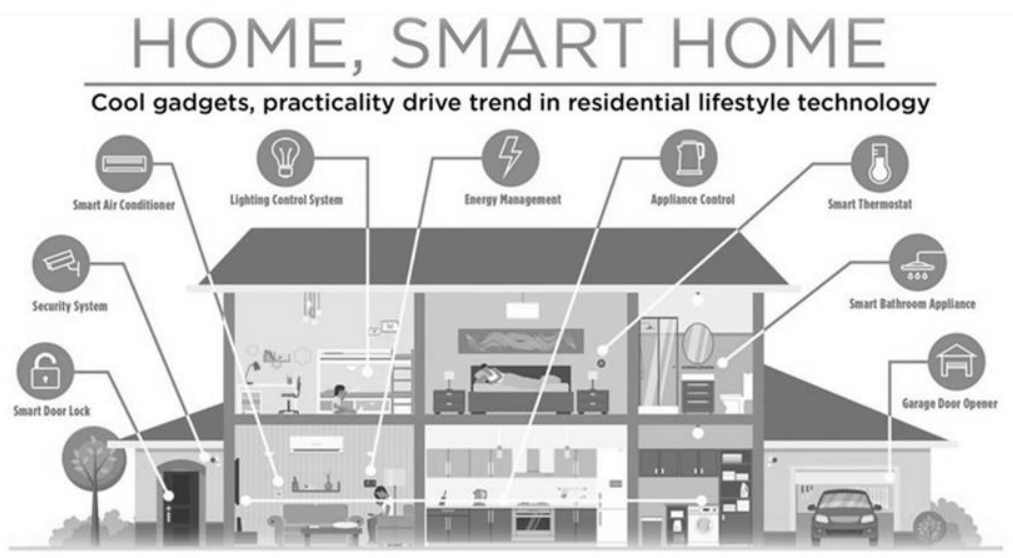

Figure 2. Smart home configuration

Raspberry Pi is a small-print computer that incorporates all the elements needed to work, created as a product of Raspberry Pi Foundation with the desire to encourage the development of computer literacy with emphasis on programming. The original model has become much more popular than it was expected to be sold out of a targeted market (eg in a robotics). By 2016, 11 million devices were sold, which is the best-selling British computer of all time [7][9].

The base of Rasperry Pi computers consists of Broadcom chips that are responsible for the central ARM processor (700 MHz ARM1176JZF-S core ARM11 family) and a graphical processor (Broadcom VideoCore IV, OpenGL ES 2.0, MPEG-2 and VC-1, 1080p30 h.264 / MPEG -4 AVC high-profile decoder and encoder). The operating memory is $256 \mathrm{MB}$ (A model), ie $512 \mathrm{MB}$ (B model).

The base also consists of 21 GPIO 3.3V data lines and 10/100 Ethernet module for wired network and USB hub with 2 external ports [21] [19].

\section{CONCLUSIONS}

This work has shown that Raspberry Pi as a widespread platform for IoT projects is very good for such projects. It has also been shown that MQTT as a system for connecting IoT devices is very flexible and easy to use. For the entire programming, Python programming language is used, which is convenient for such projects because it is very simple and easy to use. It has been shown to be well-used by a widespread platform such as Raspberry Pi because of its readability and a very large online community that allows sharing of ideas and programming code.

Testing was done so that Raspberry Pi was included in the home router. The power is supplied via a micro USB cable and a mobile charger. After booting, Raspberry sends its IP address to the selected e-mail. If this IP address is entered in a web browser, and if the computer / mobile phone is in the same local network as Raspberry, then the data management and visualization page is accessed. If your computer or cell phone is not in the local network, you must manually launch the file index.html. In this paper, it has been shown that easy-to-access platforms and open code can easily make visible results in the Internet of Things paradigms. Using easily accessible materials, it is possible to achieve results that are easy to apply in practice, industry and science. 


\section{REFERENCES}

[1] A. Papp, L. Szilassy, J. Sárosi: (2016) "Navigation of Differential Drive Mobile Robot on Predefined, Software Designed Path", Recent Innovations in Mechatronics (RIiM), Vol. 3, No. 1-2, ISSN 20649622, 1-5.

[2] Chirila S, Lemnaru C, and Dinsoreanu M. (2016) Semantic-based IoT device discovery and recommendation mechanism. In Proceedings of the 2016 IEEE 12th International Conference on Intelligent Computer Communication and Processing (ICCP'16), 111-116.

[3] Gyorgy Terdik, Zoltan Gal (2013): Advances and practice in Internet of Things: A case study, Proceedings of IEEE 4th International Conference on Cognitive Infocommunications (CogInfoCom 2013), Budapest, Hungary, December 2-5, 2013, ISBN: 978-1-4799-1544-6, 435-440.

[4] Gyula Mester, Aleksandar Rodic, Sensor-Based Intelligent Mobile Robot Navigation in Unknown Environments, International Journal of Electrical and Computer Engineering Systems, Vol. 1, No. 2, pp. 1-8, ISSN: 1847-6996, 2010.

[5] Habibi, Robet. (2017)"Perencanaan sistem smart academic dengan smart classroom dan teknologi internet of things pada stmik bina patria." jurnal transformasi 13.1.

[6] http://www.ibm.com/bluemix/.

[7] Imre Petkovics, János Simon, Ármin Petkovics, Zlatko Čović, (2017) "Selection of Unmanned Aerial Vehicle for Precision Agriculture with Multi-criteria Decision Making Algorithm", Proceedings of the Conference SISY 2017, pp. 1-5, Subotica, Serbia.

[8] J. Sárosi (2014): Measurement and Data Acquisition, University of Szeged, Faculty of Engineering, Szeged, ISBN 978-963-306-284-5, $100 \mathrm{p}$.

[9] János Simon, Monika Trojanova, Jozef Zbihlej, József Sarosi, (2018) "Mass Customization Model in Food Industry Using Industry 4.0 Standard with Fuzzy Based Multi-criteria Decision Making Methodology", Advances in Mechanical Engineering Vol.10, No.3, 1-18.

[10] János Simon, Zlatko Čović, Dalibor Dobrilović, (2016) "The Web of Things and Database Management Systems", Analecta Technica Szegedinensia, Vol 10, No 2, 61-68.

[11] Khan, Rafiullah, et al. (2012) "Future internet: the internet of things architecture, possible applications and key challenges." Frontiers of Information Technology (FIT), 2012 10th International Conference on. IEEE.

[12] Khari, Manju, et al. (2016) "Internet of Things: Proposed security aspects for digitizing the world." Computing for Sustainable Global Development (INDIACom), 2016 3rd International Conference on. IEEE.

[13] Mehta, Vishal. (2018) "A Novel Approach to Realize Internet of Intelligent Things." Big Data Analytics. Springer, Singapore, 413-419.

[14] Mohammad Abdullah Al Faruque and Korosh Vatanparvar. (2016) Energy management-as-a-service over fog computing platform. IEEE Int. Things J. 3, 2, 161-169.

[15] Nukala R, et al. (2015) An IoT based approach towards Global Food Safety and Security. In: The 14th IT\&T Conference, 10-17.

[16] Nyikes, Z., Rajnai, Z. (2015) "The Big Data and the relationship of the Hungarian National Digital Infrastructure", International Conference on Applied Internet and Information Technologies, ICAIIT 2015, 6-12.

[17] Odry, Á., J. Fodor, and P. Odry. (2016) "Stabilization of a two-wheeled mobile pendulum system using LQG and fuzzy control techniques." International Journal On Advances in Intelligent Systems 9.1 .

[18] Simon János, (2015) “Concepts of the Internet of Things from the Aspect of the Autonomous Mobile Robots”, Interdisciplinary Description of Complex Systems Vol.13 No.1, 34-40. 
[19] Simon János, Matijevics István, „Distant Monitoring And Control For Greenhouse Systems Via Internet”, Zbornik radova konferencije Yuinfo 2009, pp. 1-3, Kopaonik, Srbija, 2009.

[20] Simon János, Zlatko Covic, (2015) "Data Management of the Automomous Mobile Devices and Internet of Things", ANNALS of Faculty Engineering Hunedoara - International Journal of Engineering Vol. XIII, No. 3, 265-268.

[21] Simon János, Zlatko Čović, Igor Fürstner, Laslo Gogolak, Dalibor Dobrilović, (2015) "The Web of Things and Database Services", Proceedings of the International conference on Applied Internet and Information Technologies AIIT 2015, 235-238.

[22] Simon János, Zlatko Covic, Imre Petkovic, (2017) "Industrie 4.0 Based Customized Mass Production Overview", Proceedings of the Conference MECHEDU 2017, 1-5.

[23] U. Alvarado, A. Juanicorena, I. Adin, B. Sedano, I. Gutirrez, and J. de Nó. (2012) Energy harvesting technologies for low-power electronics. Trans. Emerg. Telecommun. Technol. 23(8), 728-741.

[24] Xiaorong Z, et al. (2015) The design of the internet of things solution for food supply chain. In: 5th International Conference on Education, Management, Information and Medicine, Shenyang, China, 314-318,

[25] Židek K, et al. (2016) Embedded vision equipment of industrial robot for inline detection of product errors by clustering-classification algorithms. Int. J. Adv. Robot. Syst., 13(5): 1-10. 